\title{
HIV Drug Resistance Program
}

National Cancer Institute

\section{Source}

National Cancer Institute. HIV Drug Resistance Program. NCI Thesaurus. Code C16101.

This HIV initiative will create a center for retrovirology research, with emphasis on basic and translational research related to viral evolution and resistance biology. Scientific issues to be addressed in solving the problem of HIV drug resistance will require the coordinated efforts of experts in structural biology and biochemistry, molecular and clinical or in vivo virology, epidemiology, and chemistry. The new prog ram also will include animal model studies of population dynamics and population genetics of HIV, mathematical modeling of virus populations and evolution, and, ultimately, translation of the findings into drug development. 